\title{
BMJ Open UK cardiac rehabilitation fit for purpose? A community-based observational cohort study
}

\author{
Saïd Ibeggazene (D) , ${ }^{1}$ Chelsea Moore, ${ }^{2}$ Costas Tsakirides, ${ }^{3}$ Michelle Swainson, ${ }^{4}$ \\ Theocharis Ispoglou, ${ }^{3}$ Karen Birch ${ }^{1}$
}

To cite: Ibeggazene S, Moore C, Tsakirides C, et al. UK cardiac rehabilitation fit for purpose? A community-based observational cohort study. BMJ Open 2020;10:e037980. doi:10.1136/ bmjopen-2020-037980

- Prepublication history for this paper is available online. To view these files, please visit the journal online (http://dx.doi. org/10.1136/bmjopen-2020037980).

Received 01 March 2020 Revised 18 August 2020 Accepted 28 August 2020

\section{A) Check for updates}

(c) Author(s) (or their employer(s)) 2020. Re-use permitted under CC BY-NC. No commercial re-use. See rights and permissions. Published by BMJ.

${ }^{1}$ School of Biomedical Sciences, University of Leeds, Leeds, UK ${ }^{2}$ Department of Sport and Exercise Sciences, Wrexham Glyndwr University, Wrexham, UK

${ }^{3}$ Carnegie School of Sport, Leeds Beckett University School of Sport, Leeds, UK

${ }^{4}$ Lancaster University Lancaster Medical School, Lancaster, UK

Correspondence to Dr Saïd lbeggazene; said.ibeggazene@gmail.com

\section{ABSTRACT}

Objectives This study aimed to characterise the exercise performed in UK cardiac rehabilitation (CR) and explore relationships between exercise dose and changes in physiological variables.

Design Observational cohort study.

Setting Outpatient community-based CR in Leeds, UK. Rehabilitation sessions were provided twice per week for 6 weeks.

Participants Sixty patients (45 male/15 female 33-86 years) were recruited following referral to local outpatient CR.

Outcome measures The primary outcome was heart rate achieved during exercise sessions. Secondary outcomes were measured before and after CR and included incremental shuttle walk test (ISWT) distance and speed, blood pressure, brachial artery flow-mediated dilatation, carotid arterial stiffness and accelerometer-derived habitual physical activity behaviours.

Results The mean \% of heart rate reserve patients exercised at was low and variable at the start of $\mathrm{CR}$ $(42 \% \pm 16 \%)$ and did not progress by the middle $(48 \% \pm 17 \%)$ or end $(48 \% \pm 16 \%)$ of the programme. ISWT performance increased following CR $(440 \pm 150 \mathrm{~m}$ vs $633 \pm 217 \mathrm{~m}, \mathrm{p}<0.001$ ); however, blood pressure, body weight, endothelial function, arterial stiffness and habitual physical activity behaviours were unchanged following 6 weeks of CR ( $p>0.05)$.

Conclusion Patients in a UK CR cohort exercise at intensities that are variable but generally low. The exercise dose achieved using this CR format appears inadequate to impact markers of health. Attending CR had no effect on physical activity behaviours. Strategies to increase the dose of exercise patients achieve during CR and influence habitual physical activity behaviours may enhance the effectiveness of UK CR.

\section{INTRODUCTION}

Cardiac rehabilitation (CR) is a multidisciplinary intervention for people recovering from adverse cardiac events. ${ }^{1}$ CR services are used by over 100000 patients annually in the UK, equating to over $50 \%$ of eligible patients, with uptake growing in recent years. ${ }^{2}$ Approximately $80 \%$ of this service is delivered as supervised exercise rehabilitation typically within hospital and community-based centres.

\section{Strengths and limitations of this study}

The study population reflects a heterogeneous 'realworld' cohort from multiple centres.

- The description of exercise intensities used in this study was derived in the same manner as applied in standard practice and not from cardiopulmonary exercise testing.

- The size of the sample cohort was insufficient to draw conclusions regarding the impact of exercise intensity on short-term outcomes following cardiac rehabilitation.

- This study may not reflect regional variability in cardiac rehabilitation practice.

Recently, the effectiveness of UK CR was called into question following the publication of the 'Rehabilitation after myocardial infarction trial ${ }^{3}$ (RAMIT), the largest randomised controlled trial (RCT) in the era of modern CR. Using a pragmatic design, it observed no beneficial impact of participating in outpatient CR on patients' all-cause mortality, cardiovascular morbidity, risk factors, healthrelated quality of life or self-reported daily level of physical activity (PA).

In contrast to previous meta-analyses, ${ }^{1}$ a recent Cochrane review of RCTs comparing non-participation to participation in CR found no effect on all-cause mortality (risk ratio $=0.96 ; 95 \%$ CI 0.88 to 1.04 ) and only modest effects on cardiovascular mortality (risk ratio $=0.74 ; 95 \%$ CI 0.64 to 0.86$).{ }^{4}$ Comprising $~ 13 \%$ of patients, the outcomes of the review were heavily impacted by the RAMIT. $^{3}$ The failure of recent RCTs to support the effectiveness of $\mathrm{CR}^{5}$ has caused speculation as to whether potential health gains from exercise-based CR have diminished in the context of contemporary cardiovascular disease (CVD) treatments ${ }^{4}{ }^{6}$ and whether RCTs represent real-world CR populations. ${ }^{7}$

The primary therapeutic component of CR is exercise training, which mitigates many risk 
factors key to secondary CVD prevention when provided in a sufficient dose. The strongest prognostic marker in patients with coronary artery disease is cardiorespiratory fitness, ${ }^{8-10}$ a biomarker primarily responsive to exercise training. A $12 \%-15 \%$ decrease in all-cause mortality has been observed per $1 \mathrm{~mL} / \mathrm{kg} / \mathrm{min}$ increase in cardiorespiratory fitness. ${ }^{811}$ Additionally, exercise training in CR can improve CVD risk factors such as lipid profiles, ${ }^{12}$ cardiac function/reverse remodelling, ${ }^{13}$ vascular endothelial function, ${ }^{14}$ arterial stiffness, ${ }^{15}$ blood pressure ${ }^{16}$ and body composition. ${ }^{17}$ These exercise studies are varied in terms of the durations, frequencies and intensities used within their exercise training programme, yet consistently report increases in cardiorespiratory fitness alongside other health parameters, suggesting that a sufficient treatment dose was achieved. The lack of positive outcomes following CR in the RAMIT ${ }^{3}$ thus appear counterintuitive. However, the various effects of exercise training, like many treatments, are dose dependent and the dose of exercise performed in the RAMIT and its acute physiological effects are unknown. Accordingly, the RAMIT results may indicate an underdosage of exercise. ${ }^{18}$

A potential explanation may relate to a culture of low intensity exercise used in UK CR compared with elsewhere. There is a paucity of literature reporting characteristics of the exercise therapy actually achieved-not simply prescribed-by patients in UK CR or worldwide. ${ }^{19}$ Gains in cardiorespiratory fitness in UK cohorts may be minimal $^{20}$ and are lower relative to those in Europe and North America (+0.52vs +1.55 metabolic equivalents), ${ }^{21}$ in part related to a lower number of exercise sessions performed in UK CR. ${ }^{22}$ The contribution of exercise intensity to these substandard fitness gains following UK CR is unclear though there are indications the exercise intensity in routine care is quite low. ${ }^{20}$ In UK CR, with limited resource to increase session number or duration, the intensity of exercise becomes the predominant mediator of the achievement of an effective dose of exercise. The contribution of exercise intensity to these substandard fitness gains following UK CR is unclear. As Savage ${ }^{23}$ highlights, those patients who fail to improve cardiorespiratory fitness following CR tend to exercise at a lower mean intensity. The beneficial effects of exercise-based CR on health are not solely attributable to immediate gains in fitness. In addition to providing an opportunity to address classical cardiovascular risk factors, this short period of exercise training may enhance endothelial function by $\sim 2 \%{ }^{24-26}$ and facilitate the adoption of a more physically active lifestyle in populations with cardiovascular disease.

To further our understanding of the contributions of exercise to patient health outcomes following real-world CR and contextualise historical findings, it is necessary to describe the characteristics of the exercise dose achieved by patients. We hypothesised that the intensity of exercise performed by patients undertaking CR in a UK-based cohort would be low and that the CR programme would not impact short-term health outcomes. Therefore,

\begin{tabular}{|c|c|}
\hline Baseline characteristics $(n=60)$ & \\
\hline Sex (\% male) & 75 \\
\hline Age (years) & $63 \pm 12$ \\
\hline Height (m) & $1.71 \pm 0.10$ \\
\hline Weight (kg) & $81 \pm 15$ \\
\hline Systolic blood pressure $(\mathrm{mm} \mathrm{Hg})$ & $128 \pm 20$ \\
\hline Diastolic blood pressure (mm Hg) & $70 \pm 10$ \\
\hline Diabetic (\%) & $15 \%$ \\
\hline \multicolumn{2}{|l|}{ Cardiac event (\%) } \\
\hline Myocardial infarction & 75 \\
\hline Coronary artery bypass graft & 25 \\
\hline Percutaneous coronary intervention & 62 \\
\hline $\begin{array}{l}\text { Myocardial infarction+percutaneous coronary } \\
\text { intervention }\end{array}$ & 45 \\
\hline Days since cardiac event & $70 \pm 31$ \\
\hline Myocardial infarction & $75 \pm 30$ \\
\hline Coronary artery bypass graft & $71 \pm 31$ \\
\hline Percutaneous coronary intervention & $102 \pm 20$ \\
\hline $\begin{array}{l}\text { Myocardial infarction+percutaneous coronary } \\
\text { intervention }\end{array}$ & $69 \pm 28$ \\
\hline \multicolumn{2}{|l|}{ Medication use (\%) } \\
\hline ACE inhibitors & 85 \\
\hline Antiplatelet agents & 95 \\
\hline$\beta$-adrenergic antagonists & 93 \\
\hline Statins & 89 \\
\hline Aspirin & 100 \\
\hline
\end{tabular}

Data are mean \pm SD unless otherwise stated.

we sought to characterise the exercise undertaken in a cohort of UK patients undergoing community-based CR and to examine its impact on habitual PA and vascular structure and function.

\section{METHODS}

Sixty patients (45 male; 15 female) (table 1) were recruited following referral to phase III CR within Leeds Community Healthcare NHS Trust subsequent to myocardial infarction or elective revascularisation in 2016-2018. Patients were recruited prior to CR at four centres, and those with arrythmias, heart failure, valvular disease or limited mobility were excluded. Written informed consent was gained from patients.

\section{Patient and public involvement}

Patients or the public were not involved in the design, or conduct, or reporting, or dissemination of this research.

\section{Study design}

Patients undertook an incremental shuttle walk test, ${ }^{27}$ measurements of blood pressure, height and weight with 
the CR team nurses or healthcare assistants prior to the start of the CR programme as per usual care. Patients underwent a 6-week programme of twice weekly exercise sessions and 1 weekly lifestyle education session. Immediately prior to the second exercise session, vascular assessments of arterial stiffness and endothelial function were performed. Habitual PA was assessed over 7 days via accelerometery. Exercise intensities were characterised using HR monitors in the 2nd (START), 6th or 7th (MID) and 11 th session (END) of CR. Assessment of arterial stiffness and endothelial function was repeated on the 11th exercise session after which accelerometery was repeated for a further 7 days. A second ISWT was performed, as well as measures of blood pressure and weight at a follow-up assessment clinic on completion of CR. Any changes in medication usage during the study period were recorded.

\section{Physical activity}

Advice to increase habitual PA was delivered by an experienced exercise instructor in the form of a 1-hour lecture. No formal home-based exercise programme was provided. Habitual PA was objectively measured using hip-mounted tri-axial accelerometers (ActiGraph GTX3+, Actigraph LLC, Florida, USA). Patients were instructed to wear the accelerometer for seven consecutive days and complete an adjunct wear time log. Accelerometers sampled at $30 \mathrm{~Hz}$ with data collected in $10 \mathrm{~s}$ epochs. Sample data were then reduced to $60 \mathrm{~s}$ epochs for analysis. Wear time analysis was performed using ActiLife software (ActiLife, Actigraph LLC), and a valid period of wear time was defined as $>4$ days of $>10$ hours of wear. Periods of $>60 \mathrm{~min}$ of consecutive zero readings were considered as non-wear time. Activity intensities were assigned using cut points based on those validated in a post-CR population ${ }^{28}$ as light ( $<1800$ counts/min), moderate (1800-3799 counts/min) and vigorous ( $\geq 3800$ counts $/ \mathrm{min}$ ). Moderate to vigorous PA bouts were defined as continuous periods of $>10 \mathrm{~min}$ with greater than 1800 counts $/ \mathrm{min}$. Sedentary bouts were defined as periods of valid wear time exceeding $60 \mathrm{~min}$ at $<150$ counts/min.

\section{Arterial stiffness}

Patients were instructed to arrive early to their session following a $>4$ hour fast and having abstained from alcohol ingestion, caffeine ingestion, exercise and vasodilator medication usage for $>12$ hours. Patients lay supine for $10 \mathrm{~min}$ before measures were taken and remained in this position throughout ultrasound imaging. Measures of carotid intima-media thickness and arterial compliance were measured in the right common carotid artery by ultrasound (Vivid I, GE Vingmed Ultrasound, Horten, Norway) with a $10 \mathrm{MHz}$ probe (9L, GE Vingmed Ultrasound, Horten, Norway). Images were recorded for a minimum duration of $20 \mathrm{~s}$. Two recordings in the longitudinal axis were taken $2 \mathrm{~cm}$ distal to the carotid bulb. Carotid intima-media thickness and compliance were calculated using automated edge-detection software (Vascular Research Tools 6, Medical Imaging Applications-LLC,
Iowa, USA). Carotid intima-media thickness was derived from the average intima-media thickness of the near and far carotid wall imaged in anterior and posterior planes.

Compliance was calculated as:

$$
C=(\operatorname{Dax}-D \min ) / \Delta P
$$

where $D_{\max }$ and $D_{\min }$ are the mean maxima and minima of carotid artery diameter over a 30 -s measurement period.

\section{Endothelial function}

Following the carotid examination, flow-mediated dilatation (FMD) was measured and analysed using duplex ultrasound with the same probe with adherence to guidelines. ${ }^{29}$ The probe was placed on the upper arm proximal to a blood pressure cuff placed on the forearm. Baseline measures of brachial artery diameter and blood flow were taken before inflating the cuff to $>50 \mathrm{~mm} \mathrm{Hg}$ above systolic pressure to occlude forearm blood flow for $5 \mathrm{~min}$. Images were recorded continuously from $30 \mathrm{~s}$ prior to the release of the cuff and thereafter for $3 \mathrm{~min}$, using Doppler ultrasound to record blood flow using an angle of insonation of $\leq 60^{\circ}$. Brachial artery diameter and blood flow were analysed using an automated edge-detection software (Vascular Research Tools 6). FMD was defined as the percentage change in brachial artery diameter from baseline to peak dilatation. Shear rates were estimated using measures of blood flow obtained using intensityweighted mean velocities. Shear rate was calculated for 60-s postocclusion as:

$$
\mathrm{SR}=8 \times \mathrm{VTI} / \mathrm{D}
$$

where VTI is the velocity time integral of Doppler flow and $\mathrm{D}$ is brachial artery diameter.

\section{Exercise training}

Each CR session consisted of a warm-up, 24 min of circuit training exercise (12 for $2 \mathrm{~min}$ each) and a standard cool down. All exercise stations were aerobic activities, with a mixture of 'cardiovascular' stations such as stepping, cycling or walking and 'active recovery' stations such as light dumbbell exercises or supported bodyweight exercises. Sessions were led by specialist exercise instructors and adhered to Association of Chartered Physiotherapists in Cardiac Rehabilitation guidelines, using a prescribed intensity of $40 \%-70 \%$ of heart rate reserve (HRR) and a rating of perceived exertion of $2-4$ on the Borg CR10 scale. ${ }^{30}$ Patients were presented with individualised heart rate prescriptions prior to each session on clipboards and name badges that were used by the cardiac rehab team to monitor exercise intensity. During the three sessions where HR was recorded, heart rate monitors were worn throughout (Polar RS800CX, Polar Electro, Finland) and data outputted in $5 \mathrm{~s}$ epochs. Heart rate monitors were worn during other sessions as per usual care. Resting blood pressures and heart rate were taken manually by the nursing team before and after each session as per usual practice.

Percentage HRR was calculated as: 


$$
\begin{gathered}
\mathrm{HRR}=(\mathrm{HR}-\text { resting } \mathrm{HR}) /(\mathrm{HRmax}-\text { resting HR }) \\
\text { HR } \max =205.8-(0.685 \times \text { age })
\end{gathered}
$$

where HRmax is maximum predicted HR (calculated using the Inbar formula). For patients using $\beta$-blockers, an additional 20 beats $/ \mathrm{min}$ were subtracted from maximal HR. ${ }^{30} 31$

\section{Incremental shuttle walk test}

The ISWT was performed as described by Singh et $a l^{27}$ with HR monitored via a Polar HR monitor and recorded at the end of each minute and on termination of the test. The test was terminated when a participant failed to reach more than two consecutive shuttles in time, felt unable to continue due to breathlessness or completed all twelve levels.

\section{STATISTICAL ANALYSIS}

Analysis was completed using SPSS (SPSS Statistics for Windows, V.24.0). Data were assessed for normal distribution using Shapiro-Wilk, subsequently non-normally distributed data were $\log$ transformed. Non-parametric analyses were performed on variables that remained non-normally distributed following transformation. A comparison of heart rate data between the three monitored exercise sessions was undertaken as both time spent above a series of HRR thresholds and as mean \%HRR achieved in each session and analysed via KruskallWallis, Wilcoxon-signed rank tests and one-way repeated measures analysis of variance. Groupings were identified as cardiac pathology and comorbidities (hypertension and diabetes). Further groupings were created by splitting mean heart rates per session into tertiles and by whether patients accumulated more than 8 or $12 \mathrm{~min}$ above HRR thresholds. To assess whether variables changed from pre-CR to post-CR, a general linear mixed model was used with time, pathology and comorbidity status as fixed factors and cardiovascular risk factors (blood pressure, weight and resting heart rate), measures of ISWT performance, parameters of daily PA and measures of vascular endothelial function and arterial stiffness as random effects.

Relative FMD was calculated as described elsewhere. ${ }^{32}$ To assess whether differences in vascular adaptations with training differed by cardiac pathology, these were also included within the analysis of covariance model as fixed factors.

Pearson's and Spearman correlations were performed to examine relationships between baseline values and prechange to postchanges following CR in ISWT performance variables, age, blood pressure, habitual PA, endothelial function and arterial stiffness. Alpha level was accepted as 0.05 unless stated otherwise. Missing data are enumerated in tables 2 and 3, but were excluded from statistical analyses.
Table 2 Mean time spent above HRR thresholds during each measured session

\begin{tabular}{llll}
\hline & \multicolumn{3}{l}{ Time spent above HRR threshold (min) } \\
\cline { 2 - 4 } HRR threshold & $\begin{array}{l}\text { Start } \\
(\mathbf{n}=56)\end{array}$ & $\begin{array}{l}\text { Mid } \\
(\mathbf{n}=49)\end{array}$ & $\begin{array}{l}\text { End } \\
(\mathbf{n}=46)\end{array}$ \\
\hline $40 \%$ & $14.2 \pm 11.2$ & $18.9 \pm 10.0$ & $18.4 \pm 10.3$ \\
\hline $50 \%$ & $8.9 \pm 10.1$ & $13.1 \pm 10.5$ & $12.6 \pm 11.1$ \\
\hline $55 \%$ & $6.6 \pm 9.1$ & $10.0 \pm 10.5$ & $9.7 \pm 10.5$ \\
\hline $60 \%$ & $4.8 \pm 8.0$ & $7.5 \pm 10.0$ & $7.1 \pm 9.1$ \\
\hline $65 \%$ & $3.6 \pm 7.2$ & $5.5 \pm 9.0$ & $5.2 \pm 7.8$ \\
\hline $70 \%$ & $2.5 \pm 5.9$ & $4.1 \pm 7.7$ & $3.5 \pm 6.2$ \\
\hline $80 \%$ & $1.0 \pm 3.0$ & $1.9 \pm 4.6$ & $1.4 \pm 4.2$ \\
\hline
\end{tabular}

Data are presented as mean $\pm S D$. No differences were observed between sessions $(p<0.05)$.

$\mathrm{HRR}$, heart rate reserve.

\section{RESULTS}

\section{Patient characteristics}

Patient characteristics are displayed in table 1. The proportion of males and diabetics in the sample was similar to that typically seen in UK CR $\left(70 \%\right.$ and $\left.23 \%{ }^{33}\right)$.

\section{In-exercise characteristics}

Table 2 displays the mean time per monitored session spent above HRR thresholds from $40 \%$ to $80 \%$. The mean \%HRR achieved during the three monitored exercise sessions was unchanged (start: $42 \% \pm 16 \%$, mid: $48 \% \pm 17 \%$ and end: $48 \% \pm 16 \% ; \mathrm{p}=0.06)$. Frequencies of patients accumulating at least 8 and $12 \mathrm{~min}$ above different intensities in each exercise session are displayed in table 3. The variability in heart rates achieved by patients in the START session is shown in figure 1 . The progression of exercise intensity throughout the programme is displayed in figure 2.

\section{The impact of 6 weeks of $\mathrm{CR}$}

No changes were observed in assessments of habitual PA, endothelial function or arterial stiffness following 6 weeks

Table 3 Number of patients in each measured session

\begin{tabular}{|c|c|c|c|c|c|c|}
\hline \multirow{2}{*}{$\begin{array}{l}\text { HRR } \\
\text { threshold }\end{array}$} & \multicolumn{2}{|l|}{$\begin{array}{l}\text { Start } \\
n=56\end{array}$} & \multicolumn{2}{|l|}{$\begin{array}{l}\text { Mid } \\
n=49\end{array}$} & \multicolumn{2}{|l|}{$\begin{array}{l}\text { End } \\
n=46\end{array}$} \\
\hline & $8 \mathrm{~min}$ & $12 \mathrm{~min}$ & $8 \mathrm{~min}$ & $12 \mathrm{~min}$ & $8 \mathrm{~min}$ & $12 \mathrm{~min}$ \\
\hline $40 \%$ & 36 & 31 & 38 & 37 & 34 & 33 \\
\hline $50 \%$ & 23 & 19 & 30 & 25 & 25 & 21 \\
\hline $55 \%$ & 16 & 13 & 19 & 16 & 21 & 16 \\
\hline $60 \%$ & 13 & 10 & 14 & 13 & 16 & 13 \\
\hline $65 \%$ & 10 & 6 & 12 & 11 & 12 & 9 \\
\hline $70 \%$ & 5 & 5 & 10 & 8 & 7 & 6 \\
\hline $80 \%$ & 3 & 2 & 6 & 3 & 3 & 3 \\
\hline
\end{tabular}
accumulating 8 and 12 min above HRR thresholds

HRR, heart rate reserve. 


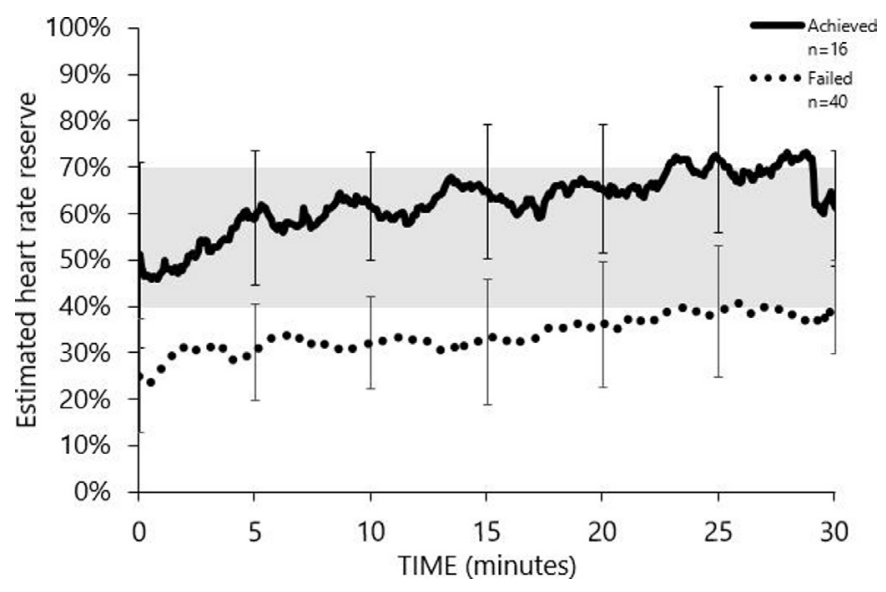

Figure 1 Mean \pm SD heart rates throughout the START session grouped for those patients who achieved $>8 \mathrm{~min}$ above 55\% HRR and those who failed to achieve this. The shaded area represents the target heart rate zone. HRR, heart rate reserve.

of CR ( $p>0.05$ : table 4). Following the CR programme, ISWT performance increases were seen in peak HR $(+14 \%)$, distance $(+44 \%)$ and speed $(+13 \%$, all $\mathrm{p}<0.001)$. Changes in walk speed and distance were correlated with the increase in peak HR achieved during the test $(\rho=0.52$; $\mathrm{p}<0.001$ and $\rho=0.49 ; \mathrm{p}<0.001$, respectively).

No adverse events were reported across the course of the study.

\section{DISCUSSION}

Our data suggest that the dose of exercise achieved by patients in an UK outpatient phase III CR programme is highly variable and predominantly performed at the lower end of the prescribed $40 \%-70 \%$ HRR range. The CR programme did not induce a change in measured cardiovascular risk factors, habitual PA or markers of vascular structure and function. These findings imply that patients accumulate an insufficient exercise dose to drive

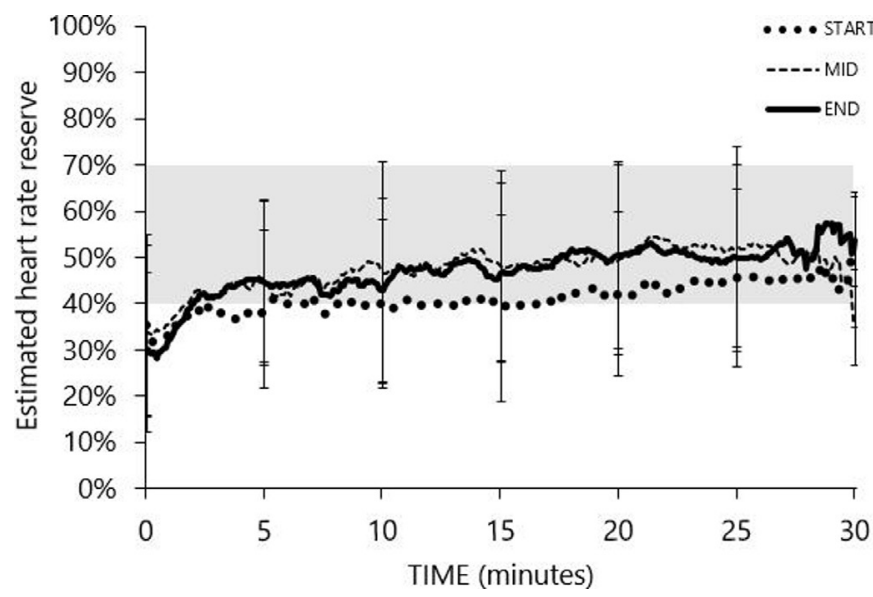

Figure 2 The progression of mean \%HRR attainment during the across the exercise programme $(n=35)$. Data are mean $\pm S D$. The shaded area represents the target heart rate zone. HRR, heart rate reserve. improvements in surrogate markers of health, suggesting that the current format of UK CR may be suboptimal.

When CR is resource limited, only exercise intensity can be manipulated without additional expenditure to modify exercise dose. Current UK CR recommendations state patients should exercise within the intensity range of $40 \%-70 \%$ of HRR. ${ }^{30}$ Patients are asked to achieve these intensities using a circuit training style programme. With this prescription, our data suggest that most patients typically exercise around the lower end of this range. Furthermore, only $\sim 30 \%$ of patients accumulated $8 \mathrm{~min}$ above $40 \%$ HRR ( a third of session duration) early in the programme, while $8 \%$ of patients failed to ever exceed this threshold during the three monitored sessions. The mean HR per session was $<55 \%$ HRR and did not progress across the 6 -week programme.

Given the dose-response relationship of exercise intensity with cardiorespiratory fitness, ${ }^{34}$ the strongest predictor of mortality in patients following $\mathrm{CR},{ }^{8-10}$ the lack of progression in exercise intensity is concerning. In exercise training programmes where the volume of exercise (frequency and duration) performed is fixed or limited by resources, the only method of modifying the dose of exercise received is by varying its intensity. A meta-regression of RCTs of CR has demonstrated that the intensity of exercise training positively influences gains in cardiorespiratory fitness. ${ }^{23} 35$ The pattern of exercise and amount of time spent at higher intensities can also have independent effects on cardiorespiratory fitness. ${ }^{34} 36$ In the present study, we did not detect an association with mean exercise intensity or time spent at higher intensities and changes in measures of vascular function or structure or habitual PA. This is partly attributable to the small number of our sample that achieved higher training intensities, the brief training period compared with non-UK cohorts ${ }^{21}$ and limitations of using HR prediction equations to prescribe exercise intensities in CR. ${ }^{38} 39$

We observed large improvements in ISWT distance $(+193 \pm 14 \mathrm{~m})$, a surrogate measure of exercise capacity, following participation in CR. This increase by far exceeds the minimally clinically meaningful difference of $70 \mathrm{~m}^{40}$ and is almost double the improvement seen in a recent RCT in a middle-income country ${ }^{41}$ despite using onethird of the total number of sessions. This unexpectedly large improvement in ISWT performance likely reflects familiarisation ${ }^{42}$ with the test plus an increase in exercise tolerance and/or effort.

PA has a dose-response relationship with CVD risk. ${ }^{43}$ Thus, modifying habitual PA following CR is essential as both a behavioural outcome contributing to secondary CVD prevention and as a driver of health gains. Indices of PA were unchanged by the CR programme in the present study. A recent systematic review and meta-analysis found PA increased with CR participation in only $\sim 25 \%$ trials assessed. ${ }^{44}$ As such, targeted and individually-tailored behavioural interventions in CR are likely needed to increase PA and provide effective secondary CVD prevention. $^{45}$ 
Table 4 Cardiovascular risk factors, ISWT performance, physical activity, endothelial function and arterial stiffness before (pre) and after (post) 6 weeks of cardiac rehabilitation

\begin{tabular}{|c|c|c|c|c|}
\hline & $\mathbf{N}$ & Pre & Post & $P$ value \\
\hline \multicolumn{5}{|l|}{ Cardiovascular risk factors } \\
\hline Weight (kg) & 57 & $81.4 \pm 15.4$ & $80.8 \pm 15.3$ & 0.82 \\
\hline Systolic blood pressure $(\mathrm{mm} \mathrm{Hg})$ & 58 & $129 \pm 20$ & $126 \pm 20$ & 0.29 \\
\hline Diastolic blood pressure $(\mathrm{mm} \mathrm{Hg})$ & 58 & $70 \pm 10$ & $70 \pm 9$ & 0.98 \\
\hline Resting heart rate (beats/min) & 58 & $64 \pm 9$ & $63 \pm 10$ & 0.41 \\
\hline \multicolumn{5}{|l|}{ ISWT performance } \\
\hline Distance (m) & 59 & $440 \pm 150$ & $633 \pm 217$ & $<0.001$ \\
\hline Speed $(\mathrm{m} / \mathrm{s})$ & 59 & $1.6 \pm 0.3$ & $1.8 \pm 0.3$ & $<0.001$ \\
\hline Peak heart rate (beats/min) & 53 & $102 \pm 13$ & $116 \pm 19$ & $<0.001$ \\
\hline \multicolumn{5}{|l|}{ Daily physical activity } \\
\hline Steps & 39 & $6390 \pm 2909$ & $6577 \pm 3789$ & 0.97 \\
\hline Sedentary activity (\%) & 39 & $41 \pm 25$ & $41 \pm 25$ & 0.52 \\
\hline Light activity (\%) & 39 & $29 \pm 21$ & $28 \pm 18$ & 0.92 \\
\hline Moderate activity (\%) & 39 & $4.5 \pm 3.2$ & $4.9 \pm 4.2$ & 0.75 \\
\hline Vigorous activity (\%) & 39 & $1.3 \pm 1.8$ & $1.5 \pm 1.9$ & 0.27 \\
\hline Sedentary activity (min) & 39 & $504 \pm 109$ & $485 \pm 95$ & 0.93 \\
\hline Light activity (min) & 39 & $296 \pm 90$ & $290 \pm 96$ & 0.64 \\
\hline Moderate activity (min) & 39 & $57 \pm 22$ & $61 \pm 34$ & 0.09 \\
\hline Vigorous activity (min) & 39 & $18 \pm 18$ & $19 \pm 20$ & 0.18 \\
\hline MVPA (min) & 39 & $75 \pm 34$ & $80 \pm 45$ & 0.72 \\
\hline MVPA bout number & 39 & $1.4 \pm 1.2$ & $1.6 \pm 1.7$ & 0.56 \\
\hline Time MVPA bouts (min) & 39 & $27 \pm 24$ & $31 \pm 32$ & 0.29 \\
\hline Time in sedentary bouts (min) & 39 & $114 \pm 87$ & $104 \pm 74$ & 0.21 \\
\hline \multicolumn{5}{|l|}{ Vascular assessments } \\
\hline Brachial arterial diameter (mm) & 26 & $4.11 \pm 0.71$ & $4.15 \pm 0.68$ & 0.78 \\
\hline Flow-mediated dilatation (\%) & 25 & $7.1 \pm 4.8$ & $4.9 \pm 4.9$ & 0.60 \\
\hline Shear stress area under the curve $60 \mathrm{~s}$ (a.u.) & 26 & $3052 \pm 1558$ & $3164 \pm 1866$ & 0.68 \\
\hline Carotid intima-media thickness (mm) & 23 & $0.73 \pm 0.11$ & $0.71 \pm 0.16$ & 0.39 \\
\hline $\begin{array}{l}\text { Carotid artery compliance } \\
\left(\mathrm{mm} \cdot \mathrm{mm} \mathrm{Hg} \cdot 10^{-3}\right)\end{array}$ & 23 & $9.0 \pm 3.9$ & $8.5 \pm 3.4$ & 0.32 \\
\hline
\end{tabular}

ISWT, incremental shuttle walk test; MVPA, moderate to vigorous physical activity.

Current attempts to address the impotence of UK CR have primarily explored operational factors (patient uptake, time since cardiac event, adherence to guidelines and provision of additional services). ${ }^{7}$ However, a potential issue with exercise-based CR evaluation is the lack of data regarding the achieved, rather than simply prescribed, exercise dose. ${ }^{19}$ This is may explain some of the heterogeneity of responses of cardiorespiratory fitness to $\mathrm{CR}$ in studies with similar exercise prescriptions. ${ }^{46}$

Our data demonstrate that the application of an exercise prescription identical to that used in the RAMIT can result in a highly variable but generally low dose of exercise (figure 2). Furthermore, this intervention does not appear adequate to improve vascular health or habitual PA: key factors in secondary CVD prevention. Thus, in combination with the relatively low total exercise volume found in $\mathrm{UK} \mathrm{CR}^{21}$ and lack of changes in fitness associated with it, ${ }^{20}$ our data displaying low exercise intensities support the notion that real-world UK CR may not currently provide a sufficient exercise dose to improve long-term health. These data suggest that poor implementation of UK CR guidelines may be partly responsible for its apparent lack of effectiveness though it cannot rule out the possibility that meeting these guidelines is not sufficient to provide effective CR. Additionally, the lack of fidelity to the exercise prescription in this study calls into question the potency of the already considerably variable exercise prescriptions across CR trials where the achieved exercise intensity is seldom verified. ${ }^{4}$ As such, future RCTs examining CR efficacy should report exercise intensities 
achieved by patients and investigate the effectiveness of higher intensity exercise prescriptions in CR.

\section{Limitations}

A shortcoming of this study is the lack of use of cardiopulmonary exercise testing to accurately assess changes in exercise capacity. Our ability to infer changes in exercise capacity from change in ISWT performance may have been limited by both a lack of an independent assessor or a lack of test familiarisation. The participants recruited to this study had a pathology of coronary artery disease; thus, this sample does not represent the heterogeneity of the wider CR population who are referred with other conditions. Due to the nature of performing assessments of endothelial function at the remote venues, it was not possible to control ambient temperature, lighting or noise levels between scans. Additionally, medication use was not prohibited prior to these assessments and menstrual cycle phase could not be controlled for in females. The small number of females included in this study has limited our ability to investigate sex and gender-related differences in engagement with and responses to routine CR-future research into this area is warranted, as is the potential to increase female recruitment more generally to CR.

\section{CONCLUSION}

The present study has characterised the exercise performed by patients in a community-based CR programme in the UK. The majority of patients spend most of CR at exercise intensities of $\sim 40 \%$ of HRR and progress little throughout the programme. There was an absence of exercise training effects on cardiovascular risk factors, measures of endothelial function and arterial stiffness. Habitual PA was unchanged. We recognise that the low dose of exercise does not negate the fact that there may have been beneficial non-physiological effects of CR participation that were not assessed in this study.

\section{Twitter Theocharis Ispoglou @Theo_Ispoglou}

Acknowledgements We would like to thank Nicki Simpson and her cardiac nursing team from Leeds Community NHS trust and the specialist exercise instructors who deliver the cardiac rehabilitation programme. Without their assistance with recruitment, insights into the practicalities of fieldwork and facilitation of our data collection, this project would not have been feasible.

Contributors All authors contributed to the design of the work. SI and CM contributed to data acquisition. SI performed data analysis. All authors contributed to data interpretation. SI and KB drafted the manuscript. CM, MS, CT and TI critically revised the manuscript. All authors gave final approval and agree to be accountable for all aspects of work ensuring integrity and accuracy.

Funding SI was supported by a Mary and Alice Smith Memorial PhD scholarship from the University of Leeds (award number N/A). CM was postgraduate research bursary from Leeds Beckett University (award number N/A).

Competing interests None declared.

Patient consent for publication Not required.

Ethics approval The study was approved by an NHS ethics committee (Research ethics committee reference: 15/WA/0404; IRAS project ID: 188338) and complied with the Declaration of Helsinki.

Provenance and peer review Not commissioned; externally peer reviewed.
Data availability statement De-identified participant data are available on reasonable request from K.M.Birch@leeds.ac.uk.

Open access This is an open access article distributed in accordance with the Creative Commons Attribution Non Commercial (CC BY-NC 4.0) license, which permits others to distribute, remix, adapt, build upon this work non-commercially, and license their derivative works on different terms, provided the original work is properly cited, appropriate credit is given, any changes made indicated, and the use is non-commercial. See: http://creativecommons.org/licenses/by-nc/4.0/.

ORCID iD

Saïd Ibeggazene http://orcid.org/0000-0001-9457-7887

\section{REFERENCES}

1 Heran BS, Chen J, Ebrahim S, et al. Exercise-based cardiac rehabilitation for coronary heart disease. Cochrane Database Syst Rev 2011;7.

2 Doherty P, Petre C, Onion N, et al. National audit of cardiac rehabilitation (NACR): annual statistical report 2017, 2018.

3 West RR, Jones DA, Henderson AH. Rehabilitation after myocardial infarction trial (RAMIT): multi-centre randomised controlled trial of comprehensive cardiac rehabilitation in patients following acute myocardial infarction. Heart 2012;98:637-44.

4 Anderson L, Oldridge N, Thompson DR, et al. Exercise-based cardiac rehabilitation for coronary heart disease: cochrane systematic review and meta-analysis. J Am Coll Cardiol 2016;67:1-12.

5 Salzwedel A, Jensen K, Rauch B, et al. Effectiveness of comprehensive cardiac rehabilitation in coronary artery disease patients treated according to contemporary evidence based medicine: update of the cardiac rehabilitation outcome study (CROSII). Eur J Prev Cardiol 2020;1:204748732090571.

6 Taylor RS, Anderson L, Oldridge N, et al. The Efficacy of ExerciseBased Cardiac Rehabilitation: The Changing Face of Usual Care. $J$ Am Coll Cardiol 2017;69:1207-8.

7 Sumner J, Harrison A, Doherty P. The effectiveness of modern cardiac rehabilitation: A systematic review of recent observational studies in non-attenders versus attenders. PloS one 2017;12:e0177658.

8 Keteyian SJ, Brawner CA, Savage PD, et al. Peak aerobic capacity predicts prognosis in patients with coronary heart disease. Am Heart J 2008;156:292-300.

9 Kavanagh T, Mertens DJ, Hamm LF, et al. Prediction of longterm prognosis in 12169 men referred for cardiac rehabilitation. Circulation 2002;106:666-71.

10 Kavanagh T, Mertens DJ, Hamm LF, et al. Peak oxygen intake and cardiac mortality in women referred for cardiac rehabilitation. J Am Coll Cardiol 2003;42:2139-43.

11 Myers J, Prakash M, Froelicher V, et al. Exercise capacity and mortality among men referred for exercise testing. $N$ Engl J Med 2002;346:793-801.

12 Yu C-M, Li LS-W, Lam M-F, et al. Effect of a cardiac rehabilitation program on left ventricular diastolic function and its relationship to exercise capacity in patients with coronary heart disease: experience from a randomized, controlled study. Am Heart J 2004;147:e24.

13 Haykowsky M, Scott J, Esch B, et al. A meta-analysis of the effects of exercise training on left ventricular remodeling following myocardial infarction: start early and go longer for greatest exercise benefits on remodeling. Trials 2011;12:92.

14 Cornelissen VA, Onkelinx S, Goetschalckx K, et al. Exercise-based cardiac rehabilitation improves endothelial function assessed by flow-mediated dilation but not by pulse amplitude tonometry. Eur $J$ Prev Cardiol 2014;21:39-48.

15 Edwards DG, Schofield RS, Magyari PM, et al. Effect of exercise training on central aortic pressure wave reflection in coronary artery disease. Am J Hypertens 2004;17:540-3.

16 Taylor RS, Unal B, Critchley JA, et al. Mortality reductions in patients receiving exercise-based cardiac rehabilitation: how much can be attributed to cardiovascular risk factor improvements? Eur J Cardiovasc Prev Rehabil 2006;13:369-74.

17 Lavie CJ, Thomas RJ, Squires RW, et al. Exercise training and cardiac rehabilitation in primary and secondary prevention of coronary heart disease. Mayo Clin Proc 2009;84:373-83.

18 Conraads VM, Denollet J, De Maeyer C, et al. Exercise training as an essential component of cardiac rehabilitation. Heart 2012;98:674-5.

19 Powell R, McGregor G, Ennis S, et al. Is exercise-based cardiac rehabilitation effective? A systematic review and meta-analysis to re-examine the evidence. BMJ open 2018;8:e019656. 
20 Nichols S, Taylor C, Goodman T, et al. Routine exercise-based cardiac rehabilitation does not increase aerobic fitness: a care $\mathrm{Cr}$ study. Int J Cardiol 2020;305:25-34.

21 Sandercock G, Hurtado V, Cardoso F. Changes in cardiorespiratory fitness in cardiac rehabilitation patients: a meta-analysis. Int J Cardiol 2013;167:894-902.

22 Sandercock GR, Cardoso F, Almodhy M, et al. Cardiorespiratory fitness changes in patients receiving comprehensive outpatient cardiac rehabilitation in the UK: a multicentre study. Heart 2013;99:785-90.

23 Savage PD, Antkowiak M, Ades PA. Failure to improve cardiopulmonary fitness in cardiac rehabilitation. J Cardiopulm Rehabil Prev 2009;29:284-91.

24 Gokce N, Vita JA, Bader DS, et al. Effect of exercise on upper and lower extremity endothelial function in patients with coronary artery disease. Am J Cardiol 2002;90:124-7.

25 Walsh JH, Bilsborough W, Maiorana A, et al. Exercise training improves conduit vessel function in patients with coronary artery disease. J Appl Physiol 2003;95:20-5.

26 Currie KD, Bailey KJ, Jung ME, et al. Effects of resistance training combined with moderate-intensity endurance or low-volume highintensity interval exercise on cardiovascular risk factors in patients with coronary artery disease. J Sci Med Sport 2015;18:637-42.

27 Singh SJ, Morgan M, Scott S, et al. Development of a shuttle walking test of disability in patients with chronic airways obstruction. Thorax 1992;47:1019-24.

28 Prince SA, Reed JL, Mark AE, et al. A comparison of accelerometer cut-points among individuals with coronary artery disease. PloS one 2015;10:e0137759.

29 Thijssen DHJ, Black MA, Pyke KE, et al. Assessment of flowmediated dilation in humans: a methodological and physiological guideline. Am J Physiol Heart Circ Physiol 2011;300:H2-12.

30 ACPICR. Association of Chartered Physiotherapists in Cardiac Rehabilition. In: Standards for physical activity and exercise in the cardiac population. 3rd ed, 2015.

31 Wonisch M, Hofmann P, Fruhwald FM, et al. Influence of beta-blocker use on percentage of target heart rate exercise prescription. Eur $J$ Cardiovasc Prev Rehabil 2003;10:296-301.

32 Atkinson G, Batterham AM. Allometric scaling of diameter change in the original flow-mediated dilation protocol. Atherosclerosis 2013;226:425-7.

33 NACR. The national audit of cardiac rehabilitation - annual statistical report. London: British Heart foundation, 2015.

34 Huang G, Wang R, Chen P, et al. Dose-Response relationship of cardiorespiratory fitness adaptation to controlled endurance training in sedentary older adults. Eur J Prev Cardiol 2016;23:518-29.

35 Uddin J, Zwisler A-D, Lewinter C, et al. Predictors of exercise capacity following exercise-based rehabilitation in patients with coronary heart disease and heart failure: a meta-regression analysis. Eur J Prev Cardiol 2016;23:683-93.

36 O'Donovan G, Owen A, Bird SR, et al. Changes in cardiorespiratory fitness and coronary heart disease risk factors following $24 \mathrm{wk}$ of moderate- or high-intensity exercise of equal energy cost. J Appl Physiol 2005;98:1619-25.

37 Kemi OJ, Haram PM, Loennechen JP, et al. Moderate vs. high exercise intensity: differential effects on aerobic fitness, cardiomyocyte contractility, and endothelial function. Cardiovasc Res 2005;67:161-72.

38 Pymer S, Nichols S, Prosser J, et al. Does exercise prescription based on estimated heart rate training zones exceed the ventilatory anaerobic threshold in patients with coronary heart disease undergoing usual-care cardiovascular rehabilitation? A United Kingdom perspective. Eur J Prev Cardiol 2020;27:579-89.

39 Hansen D, Bonné K, Alders T, et al. Exercise training intensity determination in cardiovascular rehabilitation: should the guidelines be reconsidered? Eur J Prev Cardiol 2019;26:1921-8.

40 Houchen-Wolloff L, Boyce S, Singh S. The minimum clinically important improvement in the incremental shuttle walk test following cardiac rehabilitation. Eur J Prev Cardiol 2015;22:972-8.

41 Chaves GSdaS, Ghisi GLdeM, Grace SL, et al. Effects of comprehensive cardiac rehabilitation on functional capacity in a middle-income country: a randomised controlled trial. Heart 2019;105:406-13.

42 Hakamy A, McKeever TM, Steiner MC, et al. The use of the practice walk test in pulmonary rehabilitation program: national COPD audit pulmonary rehabilitation Workstream. Int J Chron Obstruct Pulmon Dis 2017;12:2681-6.

43 Sattelmair J, Pertman J, Ding EL, et al. Dose response between physical activity and risk of coronary heart disease: a meta-analysis. Circulation 2011;124:789-95.

44 Dibben GO, Dalal HM, Taylor RS, et al. Cardiac rehabilitation and physical activity: systematic review and meta-analysis. Heart 2018;104:1394-402.

45 Hansen D, Coninx K, Dendale P, et al. The EAPC EXPERT tool Interactive training and decision support to optimize exercise prescription in cardiovascular disease: the European Association of Preventive Cardiology (EAPC) EXercise Prescription in Everyday practice \& Rehabilitative Training (EXPERT) tool. Eur Heart $J$ 2017:2318-24.

46 Mitchell BL, Lock MJ, Davison K, et al. What is the effect of aerobic exercise intensity on cardiorespiratory fitness in those undergoing cardiac rehabilitation? A systematic review with meta-analysis. $\mathrm{Br}$ Sports Med 2019;53:1341-51. 